\title{
Secondary structure as a conformational determinant in processing of peptide precursors at dibasic amino acids
}

\author{
Noureddine Lazar ${ }^{\mathrm{a}}$, Noureddine Brakch ${ }^{\mathrm{b}}$, Maï Panchal ${ }^{\mathrm{a}}$, Paul Cohen ${ }^{\mathrm{a}}$ and \\ Mohamed Rholam ${ }^{\mathrm{a}, *}$ \\ ${ }^{a}$ Laboratoire de Biochimie des Signaux Régulateurs Cellulaires et Moléculaires, \\ Université Pierre et Marie Curie, Unité Mixte de Recherches 7631 CNRS, 96, Bd Raspail, \\ 75006 Paris, France \\ ${ }^{\mathrm{b}}$ Division d'Hypertension, CHU Vaudois, CH-1011, Lausanne, Switzerland
}

\begin{abstract}
The aim of this work was to establish the functional role of selected secondary structure motifs of peptide hormone precursors in their selective recognition by the corresponding converting endoproteases. The strategy was based on the use of synthetic peptides either reproducing or mimicking the sequences of the cleavage regions of two distinct models; i.e. proocytocin-neurophysin and prosomatostatin. Both prohormones were capable to release their biologically active sequences either by cleavage at a dibasic stretch or by proteolysis at a monobasic site.

Both kinetic and thermodynamic parameters of peptide cleavage by various convertases were measured. They were examined in light of structural data on preferred conformations adopted by these substrates, which were obtained by a combination of spectroscopical techniques including CD, FT-IR and proton NMR. In the case of prosomatostatin, these approaches were in addition paralleled by site-directed mutagenesis experiments.

The wealth of collected data point toward the conclusion that $\beta$-turns and/or loops, favored by sequences bearing basic residues, constitute a key feature in the specification of those peptide loci which are proteolytically processed in vivo. They will be discussed with respect of other processing mechanisms where these mechanisms were also shown.
\end{abstract}

\section{Introduction}

Proteolytic processing is an important regulatory mechanism used by cells to control gene expression at the post-translational level. It is generally associated to mechanisms of activation or inactivation of many proteins and the regulation of their cellular localization [1-6]. Peptide hormones and peptide transmitters are generated from polypeptide precursors by specific cleavage reactions which take place principally at sites formed by single or paired basic residues [6-9]. Not all the possible cleavage sites are utilised [6,7], however, and the degree of processing of many propeptides has been found to vary according to the tissue of origin [1-5]. The restricted nature of processing reactions could point to the existence of a series of enzymes with stringent specificities $[2,4,6]$, recognising regions of structure in addition to the single or paired basic residues. Alternatively the action of processing enzymes may be directed by conformation of the pro-peptide which could focus the action of a protease onto or away from a particular site [2,7].

Earlier analysis of amino acid sequences around proteolytic cleavage sites of several biosynthetic precursors by secondary structure predictive methods [6], indicated that the dibasic residues constituting

*Corresponding author. Tel.: +331 536340 57; Fax: +331422213 98; E-mail: rholam@ccr.jussieu.fr. 
these processing sites which are cleaved in vivo are situated in, or immediately adjacent to, $\beta$-turns [6] or loops [10]. In contrast, the potential sites which are not cleaved in vivo are associated with ordered structures as $\alpha$-helices or $\beta$-sheets. Turns or loops, often associated to exposed regions in proteins [11, 12], possess a greater degree of flexibility and local mobility, compared to more rigid structures such as $\alpha$-helices and $\beta$-sheets. Therefore, the presence of turns or loops, in the vicinity of dibasic cleavage sites, is not surprising since they might favor both accessibility and adaptability of substrates to proteolytic enzymes.

The purpose of this review is to summarize the strategies and experimental approaches that were designed to analyze the role of precursor structure in the recognition of dibasic cleavage sites by their corresponding processing proteases (for reviews see $[13,14]$ ). To address this issue, the proocytocin/neurophysin (pro-OT/Np) and the prosomatostatin (ProSom) precursors were used as models.

\section{The pro-ocytocin/neurophysin model}

In this simple precursor model (Fig. 1), the $\mathrm{N}$-terminal hormone sequence (OT) is separed from the C-terminal neurophysin domain $(\mathrm{Np})$ by a "restriction" sequence $\mathrm{G}^{10}-\mathrm{K}^{11}-\mathrm{R}^{12}$ which is excised during proteolytic conversion and subsequent amidation [14]. The eicosapeptide OT/Np(1-20) (Fig. 1), corresponding to the processing domain encoded by exon I in the pro-OT/Np gene, was predicted to organize as a $\beta$-sheet $/ \beta$-turn $/ \alpha$-helix arrangement $[14,15]$. To evaluate the possible role of this structural feature in the processing of the pro-OT/Np precursor, various peptides derived from the OT/Np(1-20) domain (Table 1) were tested for their capacity to be cleaved by the pro-OT/Np convertase [16] or magnolysin [EC 3.4.24.62].

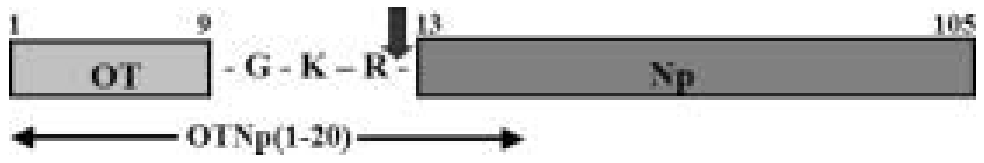

Fig. 1. A schematic representation of the 105-amino acid bovine pro-ocytocin/neurophysin I.

Table 1

Kinetic parameters for the cleavage of OT/Np-related peptides adopting $\beta$-turn, $\beta$-sheet or $\alpha$-helix conformations

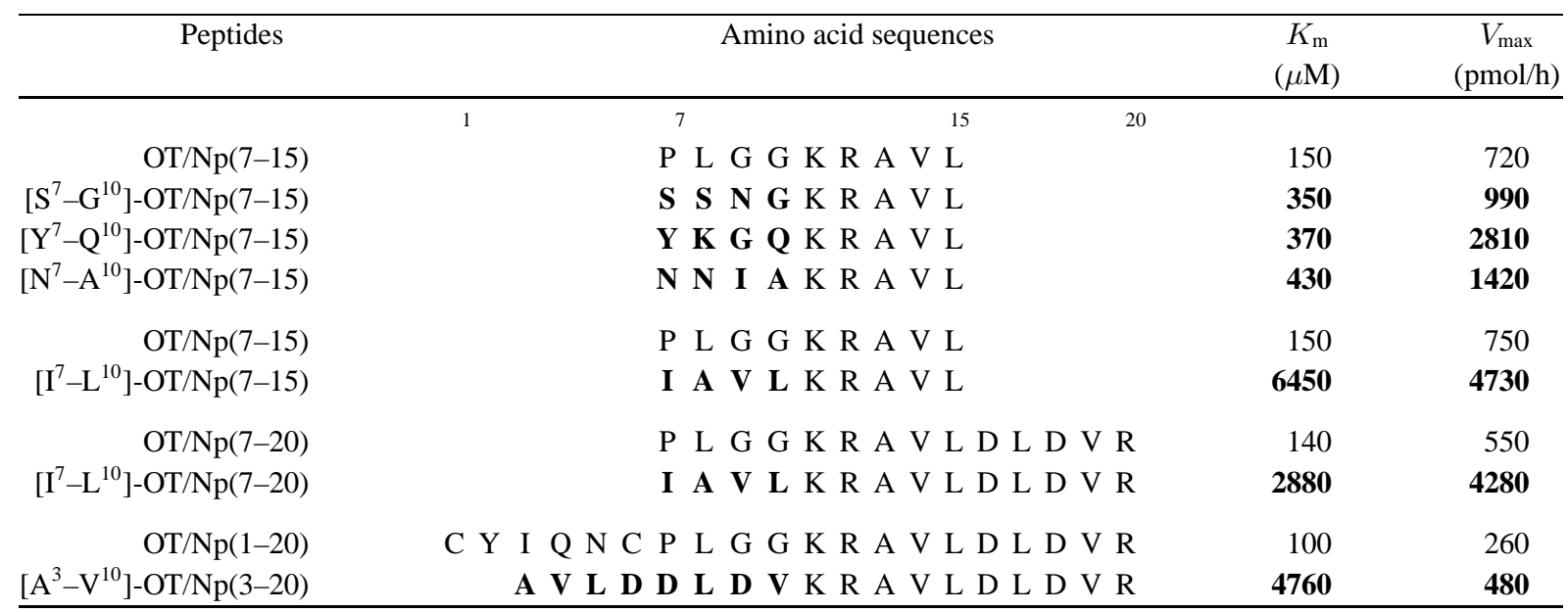




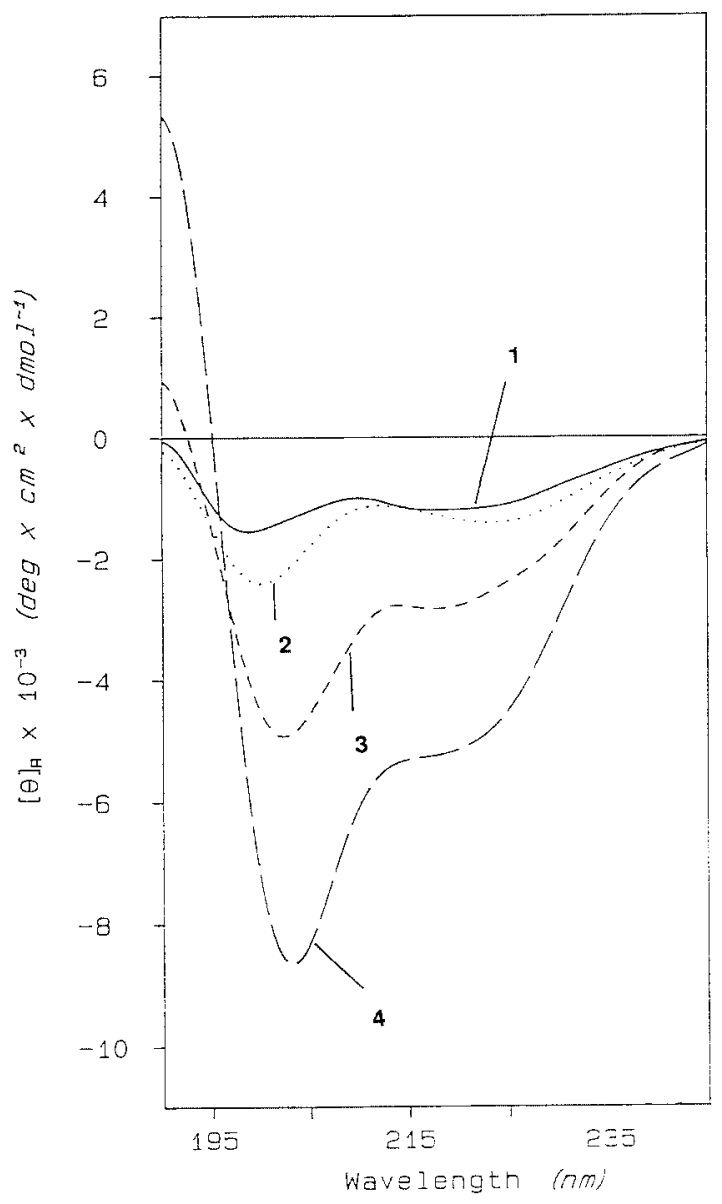

Fig. 2. Circular dichroism spectra of peptide OT/Np(8-15) (curve 1), OT/Np(7-15) (curve 2), OT/Np(8-20) (curve 3) and OT/Np(7-20) (curve 4) in 95\% TFE (from $[18,19]$ ).

\subsection{Evidence for $\beta$-turn in the vicinity of dibasic cleavage sites}

Among the tested peptides, those bearing the $\mathrm{P}^{7}-\mathrm{L}^{15}$ sequence (peptide OT/Np(7-15) in Table 1) were shown to be cleaved with high efficacy [14-17], indicating that the tetrapeptide $\mathrm{P}^{7}-\mathrm{L}-\mathrm{G}-\mathrm{G}^{10}$, predicted to adopt a $\beta$-turn structure in the processing domain [15], is essential. Accordingly, the solution conformation of certain OT/ $\mathrm{Np}(1-20)$-related peptides was performed by different spectroscopic techniques.

CD or FT-IR spectra of OT/Np(7-15) and OT/Np(7-20) peptides in mixtures of TFE/ $\mathrm{H}_{2} \mathrm{O}$ (Fig. 2) were indicative of a conformational equilibrium between aperiodic structures and folded conformations $(\beta$ turn and $\alpha$-helix) [18,19]. Since NMR analysis confirmed these observations [19], energy minimization methods (performed on the NOE data) were used to build molecular models (Fig. 3) that allowed us to draw the following conclusions:

(i) The $\mathrm{NH}_{2}$-terminal of peptides $\mathrm{OT} / \mathrm{Np}(7-15)$ and $\mathrm{OT} / \mathrm{Np}(7-20)$ involved a $\beta$-turn of type II starting from residue Pro $^{7}$. 

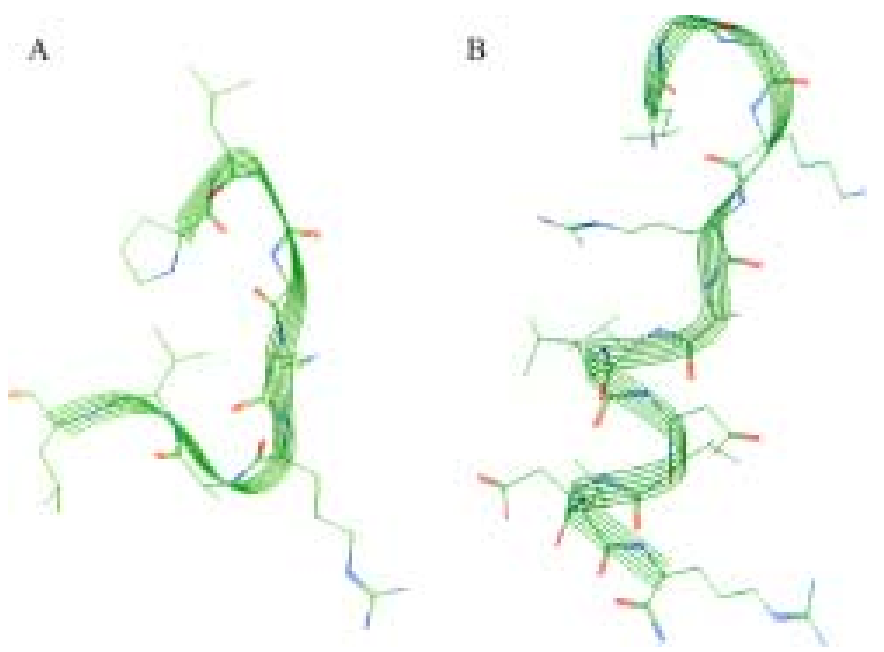

Fig. 3. Stereo views of the molecular models of peptides OT/Np(7-15) (A) and OT/Np(7-20) (B) (from [19]).

(ii) The $\mathrm{COOH}$-terminal part of the $\mathrm{OT} / \mathrm{Np}(7-20)$ peptide is characterized by an helical structure starting from the $\mathrm{Ala}^{13}$ residue, whereas this segment in the $\mathrm{OT} / \mathrm{Np}(7-15)$ peptide involves a $\beta$ turn of type II starting from residue Lys ${ }^{11}$.

These conclusions, recently confirmed by studying the $\mathrm{OT} / \mathrm{Np}(1-20)$ peptide as a model [20], support the concept that the $\beta$-turn structure might constitute a recognition signal for processing enzymes.

\subsection{The $\beta$-turn is an interchangeable structural motif}

It was previous shown that dibasic site recognition by processing endoproteases was not correlated with the existence of a consensus primary sequence but rather with the presence of $\beta$-turns or loops around these proteolytic loci $[7,10]$. Therefore, replacement of the $\mathrm{P}^{7}-\mathrm{L}-\mathrm{G}-\mathrm{G}^{10}$ sequence by nonhomologous peptide stretches, known to organize as $\beta$-turn structures in proteins [21], could not abolish the endoproteolytic cleavage of peptide $\mathrm{OT} / \mathrm{Np}(7-15)$ derivatives.

As shown in Table 1, the modified peptides ( $\left[\mathrm{S}^{7}-\mathrm{G}^{10}\right]-\mathrm{OT} / \mathrm{Np}(7-15),\left[\mathrm{Y}^{7}-\mathrm{Q}^{10}\right]-\mathrm{OT} / \mathrm{Np}(7-15)$ and $\left[\mathrm{N}^{7}-\right.$ $\left.\mathrm{A}^{10} \mathrm{]}-\mathrm{OT} / \mathrm{Np}(7-15)\right)$, as well as the reference peptide $\mathrm{OT} / \mathrm{Np}(7-15)$, were cleaved at the $\mathrm{Arg}^{12}-\mathrm{Ala}^{13}$ bond without important effects on their cleavage kinetic parameters. Verification that these nonapeptides possess the propensity to organize in $\beta$-turn conformers was performed using $\mathrm{CD}$. In $\mathrm{H}_{2} \mathrm{O}, \mathrm{CD}$ spectra of the reference peptide OT/Np(7-15) and its derivatives exhibited minima below $200 \mathrm{~nm}$, characteristic of unordered conformations [22,23]. Upon addition of 95\% TFE (Fig. 4), these peptides showed two minima around 202 and 225 and a small maximum around $190 \mathrm{~nm}$, diagnostic of $\beta$-turn structures according to the classification of Woody $[22,23]$. Together, these observations supported the hypothesis that the proteolytic processing loci share, in their vicinity, $\beta$-turn structures as a common structural feature.

In view of the general role played by this type of secondary structures in a large number of biological processes [24,25,27], $\beta$-turn structures appear to be interchangeable motifs [26] that provide readily accessible regions for selective proteases. 

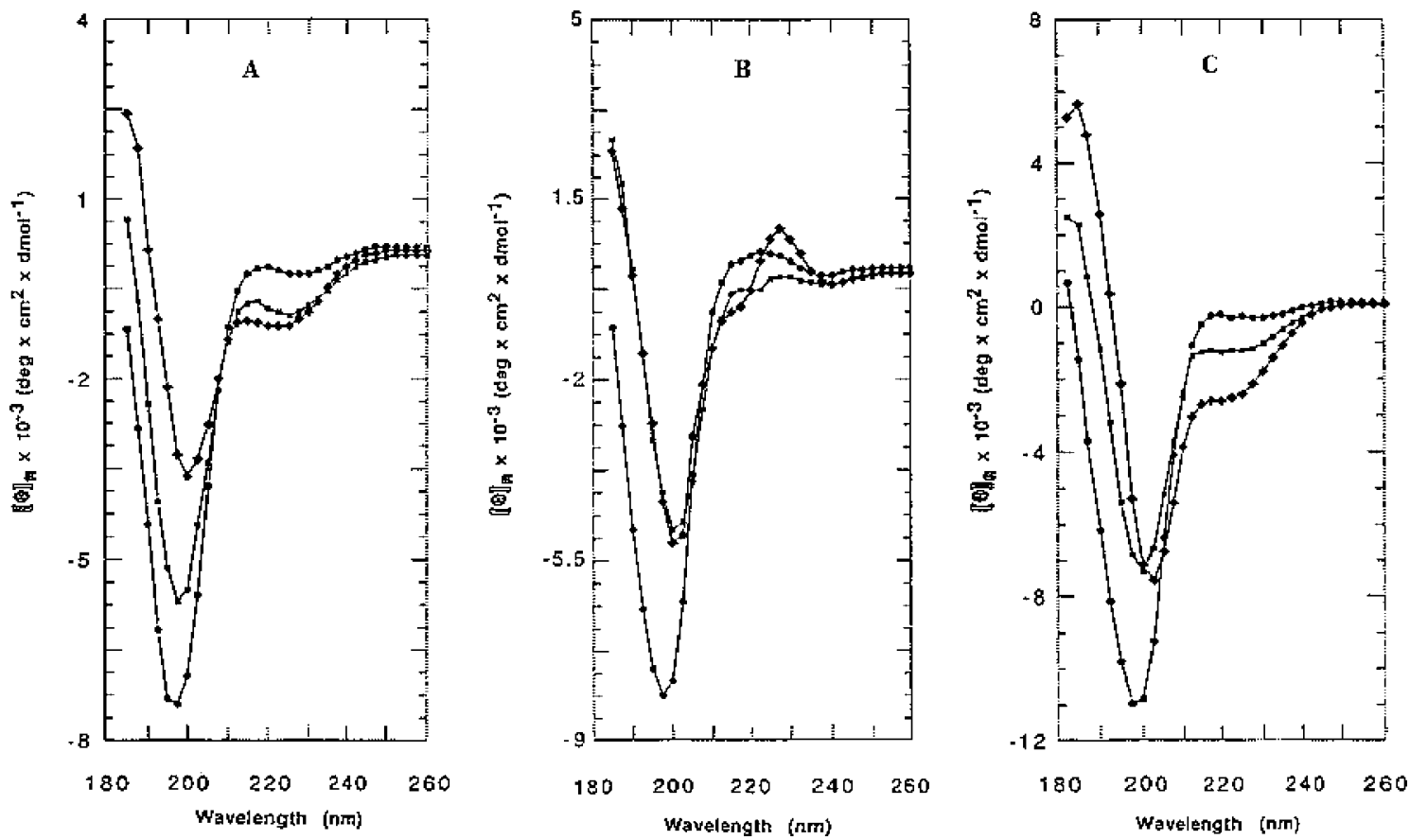

Fig. 4. Circular dichroism spectra of peptides $\left[S^{7}-G^{10}\right]-O T / N p(7-15)(A),\left[Y^{7}-Q^{10}\right]-O T / N p(7-15)$ (B) and $\left[N^{7}-A^{10}\right]-O T /$ $\mathrm{Np}(7-15)(\mathrm{C})$ in different percentages of TFE (from [21]).

\subsection{Role of $\beta$-turn in the endoproteolytic cleavage of substrates}

Since the $\beta$-turn structure appeared to be essential for the cleavage of substrates by the processing proteases, one would expect that its replacement by ordered structures might affect the kinetics of the enzymatic reaction. The peptides $\left[\mathrm{I}^{7}-\mathrm{L}^{10}\right]-\mathrm{OT} / \mathrm{Np}(7-15),\left[\mathrm{I}^{7}-\mathrm{L}^{10}\right]-\mathrm{OT} / \mathrm{Np}(7-20)$ and $\left[\mathrm{A}^{3}-\mathrm{V}^{10}\right]-\mathrm{OT} / \mathrm{Np}(1-20)$ (Table 1), designed to promote formation of $\beta$-sheet or $\alpha$-helix in the vicinity of the dibasic cleavage site [21], were used as models to test this hypothesis,

Although those substrate analogs, as well as the reference peptides OT/Np(7-15), OT/Np(7-20) and OT/ $\mathrm{Np}(1-20)$, were cleaved by the pro-OT/Np convertase, data in Table 1 reveal drastic changes in their kinetic parameters. Indeed, pairwise comparisons of peptides with the same size $\left(\mathrm{OT} / \mathrm{Np}(7-15)\right.$ and $\left[\mathrm{I}^{7}-\right.$ $\left.\mathrm{L}^{10}\right]-\mathrm{OT} / \mathrm{Np}(7-15)$; OT/Np(7-20) and $\left[\mathrm{I}^{7}-\mathrm{L}^{10}\right]-\mathrm{OT} / \mathrm{Np}(7-20)$; OT/Np(1-20) and $\left[\mathrm{A}^{3}-\mathrm{V}^{10}\right]-\mathrm{OT} / \mathrm{Np}(1-$ $20)$ ) indicated an increase in $K_{\mathrm{m}}$ of 43-, 20- and 47-fold, whereas the corresponding $V_{\max }$ values were modified only by factors 6,7 and 2, respectively (Table 1). Structural support for these in vitro data was provided by analyzing the solution conformation of those peptides (Fig. 5). In $\mathrm{H}_{2} \mathrm{O}$, the far-UV CD spectra of all the peptides were characterized by a negative band centered at $198 \mathrm{~nm}$, indicative of peptides in a random-coil conformation [22,23]. In TFE, their spectra were strongly modified. Indeed, the CD spectrum exhibited by peptide $\left[\mathrm{I}^{7}-\mathrm{L}^{10}\right]-\mathrm{OT} / \mathrm{Np}(7-15)$ (Fig. $5 \mathrm{~B}$ ) is typical of a $\beta$-sheet conformation with a negative band near $216 \mathrm{~nm}$ and a positive one between 195 and $200 \mathrm{~nm}$ [22,23]. For peptides $\left[\mathrm{I}^{7}-\mathrm{L}^{10}\right]-\mathrm{OT} / \mathrm{Np}(7-20)$ and $\left[\mathrm{A}^{3}-\mathrm{V}^{10}\right]-\mathrm{OT} / \mathrm{Np}(1-20)$, the shape of their CD spectra (Fig. 5C,D) become typical of $\alpha$-helical folding with two minima at 208 and $222 \mathrm{~nm}$ and a maximum at $193 \mathrm{~nm}$. The helix content of these two peptides, estimated from the ellipticity at $222 \mathrm{~nm}$, increased when compared to reference peptides OT/Np(7-20) (Fig. 2, curve 4) and OT/Np(1-20) (Fig. 5A), respectively. 

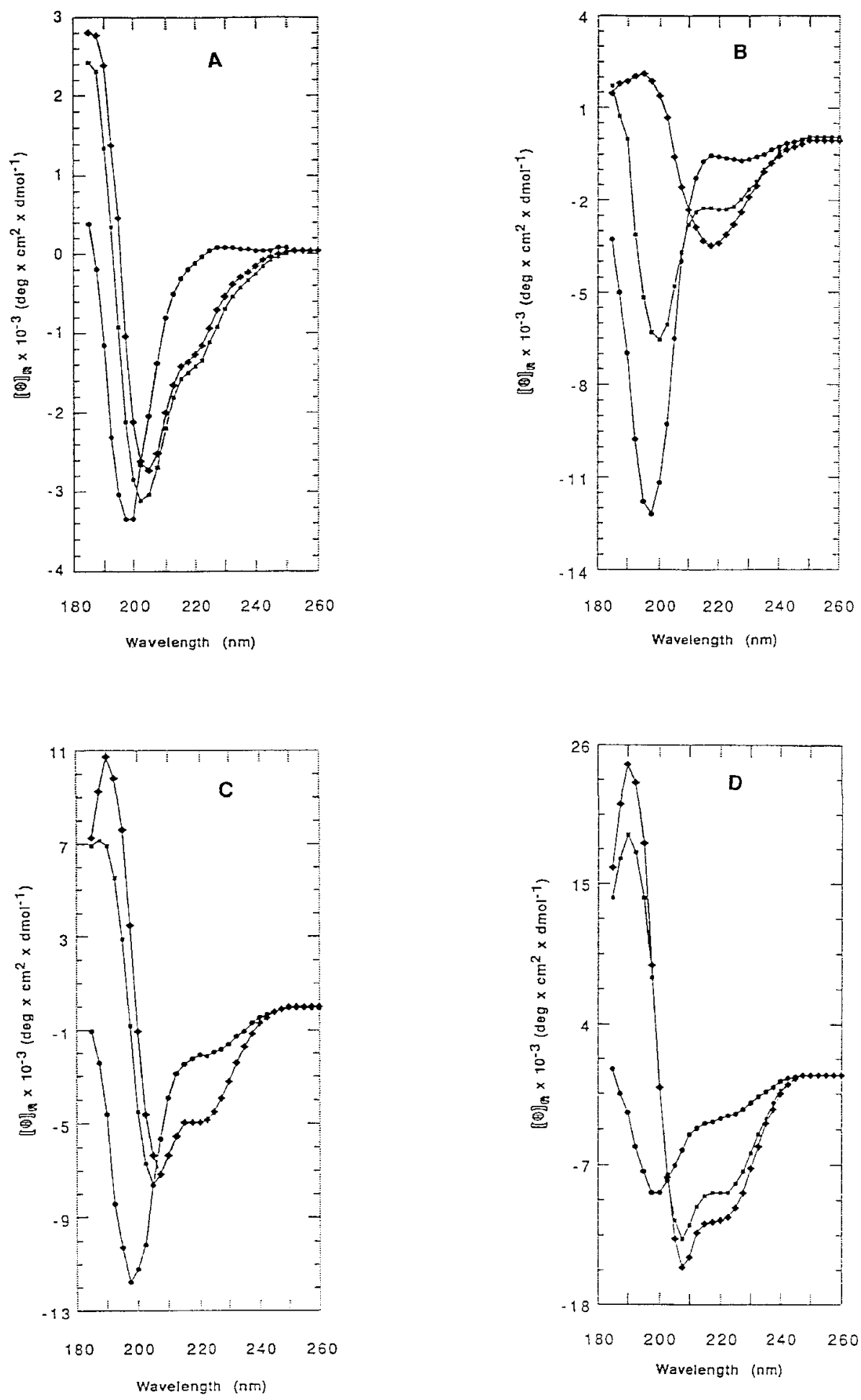

Fig. 5. Circular dichroism spectra of peptides OT/Np(1-20) (panel A), $\left[\mathrm{I}^{7}-\mathrm{L}^{10}\right]-\mathrm{OT} / \mathrm{Np}(7-15)$ (panel B), $\left[\mathrm{I}^{7}-\mathrm{L}^{10}\right]-\mathrm{OT} / \mathrm{Np}(7-20)$ (panel C) and $\left[\mathrm{A}^{3}-\mathrm{V}^{10}\right]-\mathrm{OT} / \mathrm{Np}(3-20)$ (panel D) in different percentages of TFE (from [21]). 
These data indicate that the type of secondary structure at the cleavage loci is the major determinant of the $K_{\mathrm{m}}$ value. Consequently, it can be concluded that $\beta$-turn structures, or loops, constitute recognition signals which allowed for dibasic specific convertases to discriminate between in vivo cleaved and uncleaved sites $[7,8,27]$.

\section{The prosomatostatin model}

Compared to the latter precursor, prosomatostatin (proSom) constitutes a useful model in the study of the formation of multiple hormone products by differential processing of a single polyfunctional precursor [3]. Indeed, proSom undergoes both monobasic $\left(\mathrm{R}^{-15}\right)$ and dibasic $\left(\mathrm{R}^{-2}-\mathrm{K}^{-1}\right)$ cleavages to release somatostatin-28 (S-28) and somatostatin-14 (S-14), respectively (Fig. 6). Both basic loci are separated by a dodecapeptide segment S-28(1-12) that corresponds to the $\mathrm{NH}_{2}$-terminal sequence of S-28 (Fig. 5). Secondary structure prediction on this connecting region reveals the presence of several $\beta$-turn structures $[7,14]$. In addition, the S-28(1-12) sequence includes proline residues which, by both their particular structural properties and their multiplicity in certain protein domains, play a special role in protein structure and function [28-31]. On the basis of theses observations, a combined use of site-directed mutagenesis performed on prosomatostatin substrate, with synthetic peptides selectively modified in their primary structures was adopted in order to evaluate the functional role(s) of the S-28(1-12) domain in the control of cleavage at both loci [14].

\subsection{Evidence for $\beta$-turn in the vicinity of the Arg-Lys doublet}

The existence of $\beta$-turn in the vicinity of the Arg-Lys doublet was provided by analyzing the conformation of peptides $\operatorname{Som}(-5-+5)$ and $\operatorname{Som}(-9-+5)$ (Table 2) which share the sequence involved in $\beta$-turn formation; i.e. the tetrapeptide $\mathrm{P}^{-5}-\mathrm{R}-\mathrm{E}-\mathrm{R}^{-2}$.

As shown in Fig. 7 (curve 2), the profile of CD spectrum obtained for the peptide $\operatorname{Som}(-9-+5)$ is typical of an equilibrium between $\alpha$-helix, aperiodic structures, and another component of the $\beta$-turn type [22,23]. The peptide $\operatorname{Som}(-5-+5)$, derived from peptide $\operatorname{Som}(-9-+5)$ by $\mathrm{NH}_{2}$-terminal deletion, exhibits the same spectral pattern (Fig. 7, curve 1) but the negative band around $220 \mathrm{~nm}$ decreased whereas the negative one around $203 \mathrm{~nm}$ shifted to $198 \mathrm{~nm}$ with a concomitant increase in magnitude.

These spectroscopical data, corroborated by IR spectra of both peptides (Fig. 8, panels A and B), argue in favor of the presence of $\beta$-turn in the vicinity of the basic doublet $[32,33]$.

\subsection{Role of $\beta$-turn in in vivo processing at the Arg-Lys doublet}

To test for the importance of $\beta$-turn in in vivo processing, different mutants of human prosomatostatin were constructed in which the sequence $\mathrm{P}^{-5}-\mathrm{R}-\mathrm{E}-\mathrm{R}^{-2}$ was partially or totally substituted.

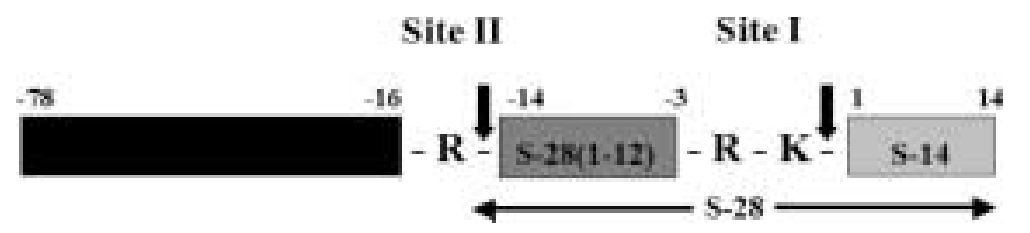

Fig. 6. A schematic representation of the 92-amino acid human prosomatostatin. Sites I and II correspond to the dibasic (RK) and monobasic $(\mathrm{R})$ cleavage loci for the production of S-14 and S-28, respectively. 
Table 2

Amino acid sequences of prosomatostatin-related peptide substrates

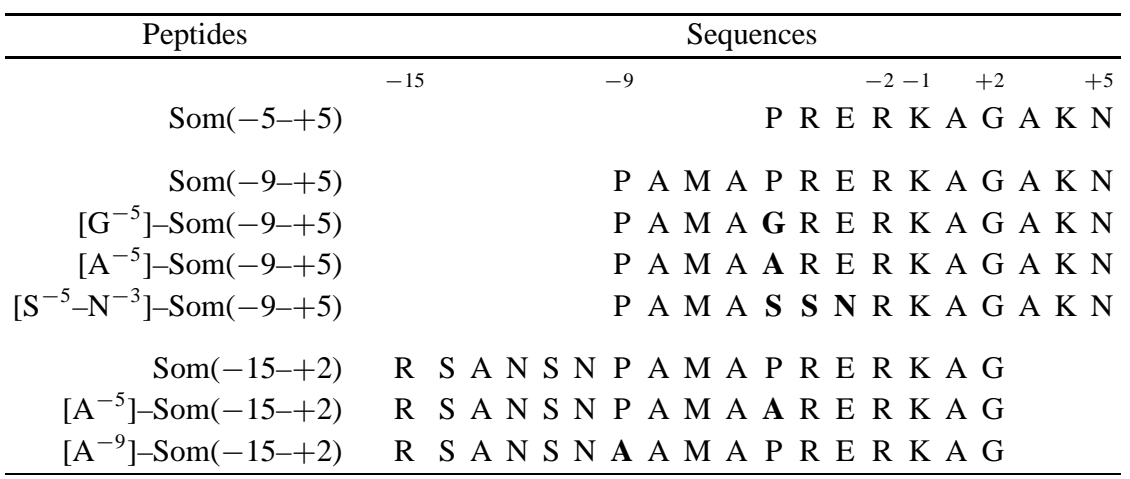

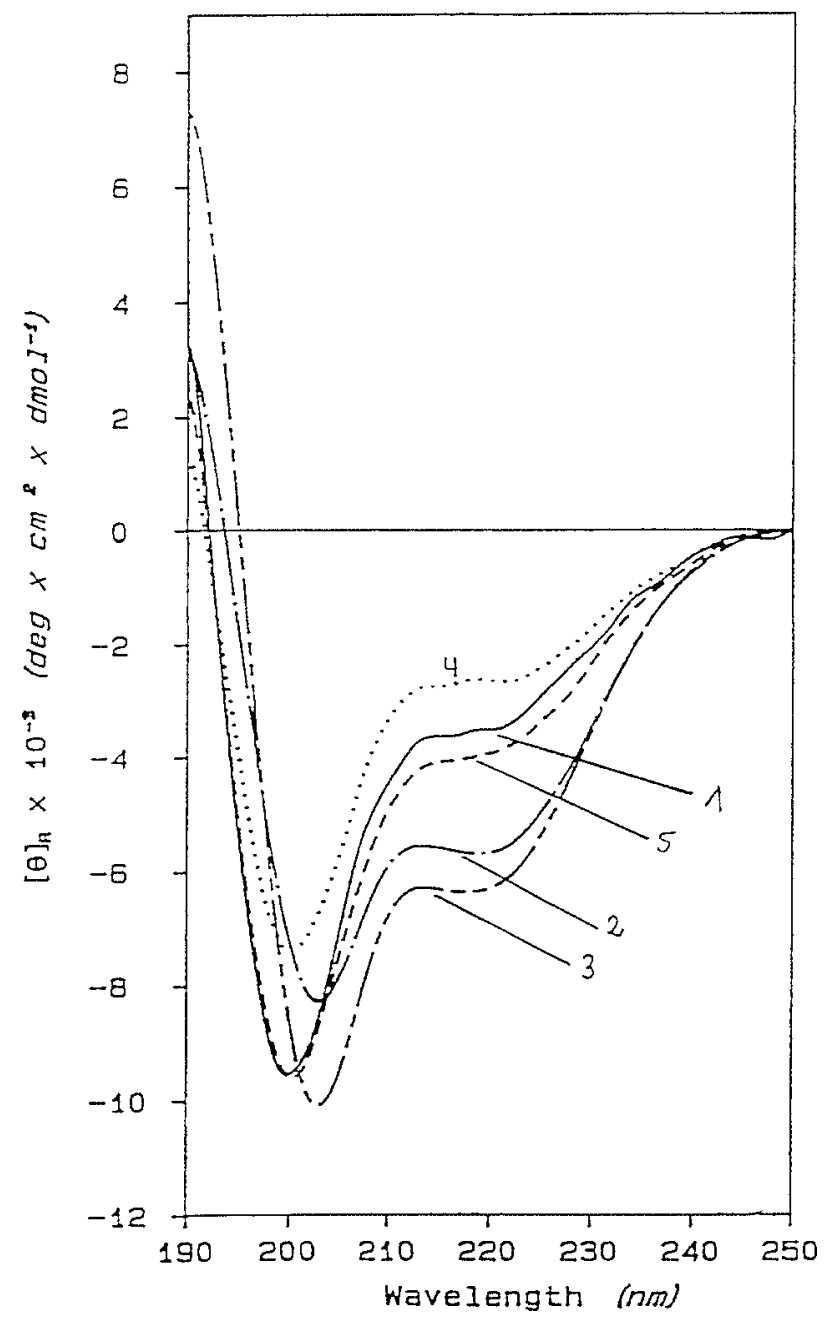

Fig. 7. Circular dichroism spectra of peptides $\operatorname{Som}(-5-+5)$ (curve 1), $\operatorname{Som}(-9-+5)$ (curve 2), $\left[\mathrm{A}^{-5}\right]-\operatorname{Som}(-9-+5)$ (curve 3), $\left[\mathrm{G}^{-5}\right]-\operatorname{Som}(-9-+5)$ (curve 4) and $\left[\mathrm{S}^{-5}-\mathrm{N}^{-3}\right]-\operatorname{Som}(-9-+5)$ (curve 5) in $95 \%$ TFE (from [33]). 


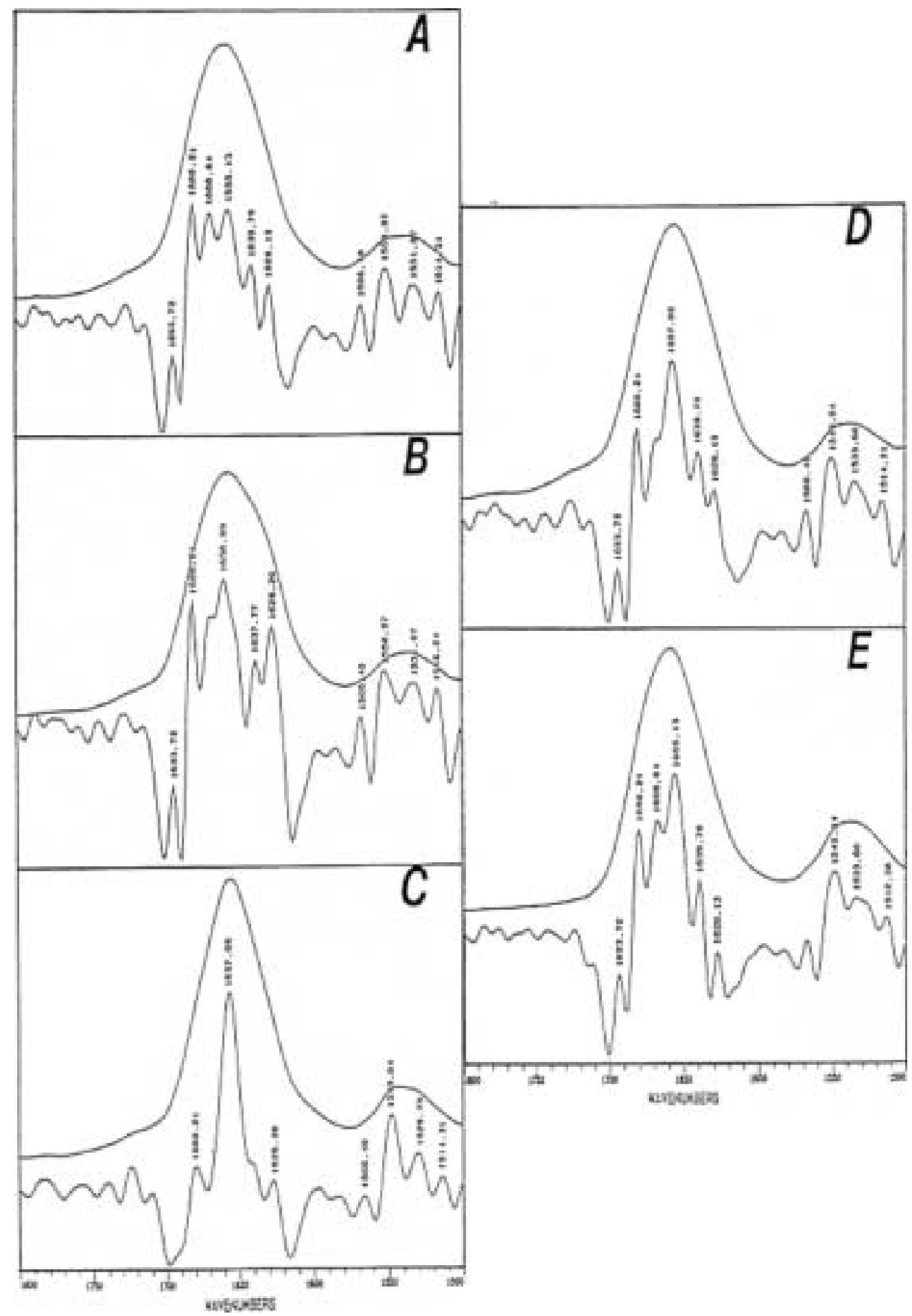

Fig. 8. Infrared spectra of peptides $\operatorname{Som}(-5-+5)$ (panel A), Som $(-9-+5)$ (panel B), $\left[\mathrm{A}^{-5}\right]-\operatorname{Som}(-9-+5)($ panel C), $\left[\mathrm{G}^{-5}\right]-\mathrm{Som}(-9-+5)$ (panel D) and $\left[\mathrm{S}^{-5}-\mathrm{N}^{-3}\right]-\operatorname{Som}(-9-+5)$ (panel E) in $95 \%$ TFE (from [33]). 
Table 3

Effects of various mutations on prosomatostatin processing in transfected Neuro2A cells

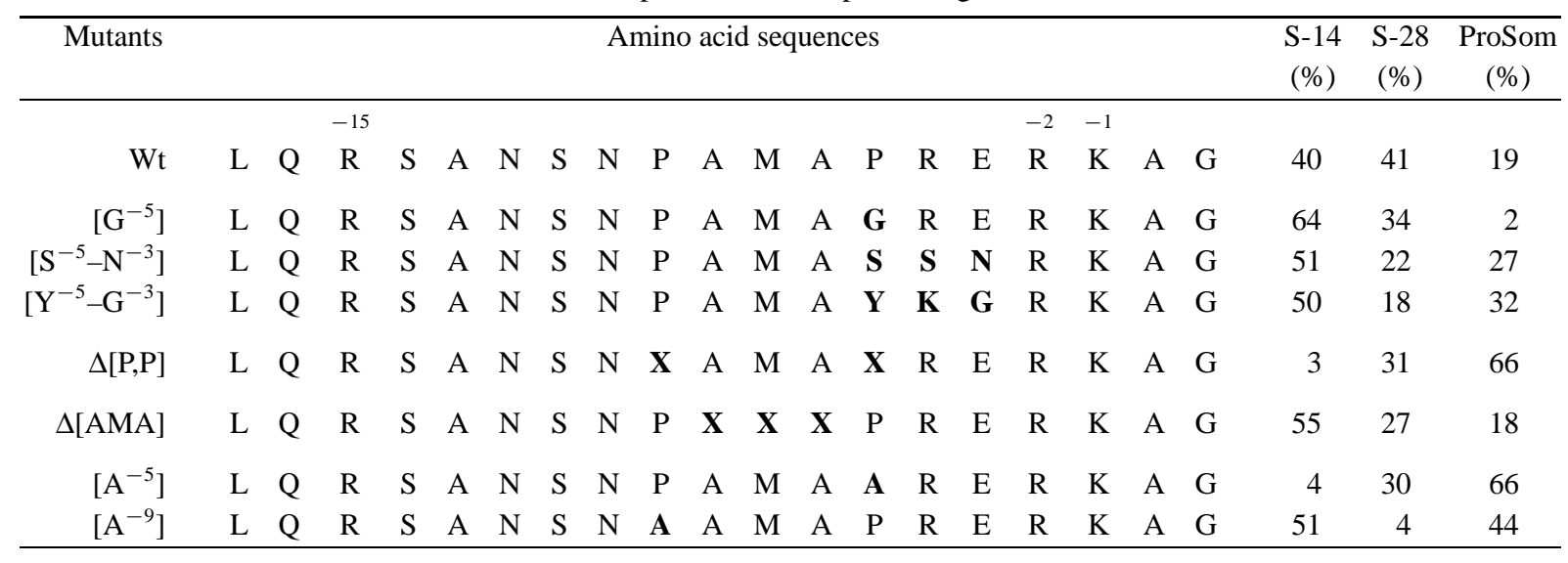

Analysis of the processing efficiencies observed with the $\left[\mathrm{S}^{-5}-\mathrm{N}^{-3}\right],\left[\mathrm{Y}^{-5}-\mathrm{G}^{-3}\right],\left[\mathrm{G}^{-5}\right]$ and $\left[\mathrm{A}^{-5}\right]$ mutants (Table 3) in transfected Neuro2A cells, indicated that only the Ala mutation abolished cleavage at the dibasic site [32,33]. Therefore, substitution of $\mathrm{P}^{-5}$ by an $\alpha$-helix promoting amino acid residue ([A $\left.\mathrm{A}^{-5}\right]$ mutant) impairs $\mathrm{S}-14$ production in prosomatostatin. In contrast, replacement of the $\mathrm{P}^{-5}-\mathrm{R}-$ E- $\mathrm{R}^{-2}$ sequence by nonhomologous peptide stretches $\left(\left[\mathrm{S}^{-5}-\mathrm{N}^{-3}\right]\right.$ or $\left[\mathrm{Y}^{-5}-\mathrm{G}^{-3}\right]$ mutants), capable of adopting an equivalent secondary structure, or of $\mathrm{P}^{-5}$ by a $\beta$-turn "former" residue-like ( $\left[\mathrm{G}^{-5}\right]$ mutant) did not affect prosomatostatin processing.

Structural analysis of peptides reproducing these mutations (Table 2), supports these in vivo data. Indeed, in comparison to the reference peptide $\operatorname{Som}(-9-+5)$ (Fig. 7, curve 3), the CD spectra of the $\left[\mathrm{G}^{-5}\right]-\operatorname{Som}(-9-+5)$ and $\left[\mathrm{S}^{-5}-\mathrm{N}^{-3}\right]-\operatorname{Som}(-9-+5)$ peptides (Fig. 7, curves 4 and 5) are characterized by an increased amount of $\beta$-turn and unordered conformations in agreement with their computed secondderivate IR spectra (Fig. 8, panels D and E). For the peptide $\left[\mathrm{A}^{-5}\right]-\operatorname{Som}(-9-+5$ ), its CD spectrum (Fig. 7, curve 2) shows in contrast, a significant increase in magnitude of the band at $190 \mathrm{~nm}$ (contribution from $\alpha$-helix) and its second-derivate IR spectrum (Fig. 8, panel C) exhibits a significant increase of the $\alpha$-helix component $\left(1657 \mathrm{~cm}^{-1}\right.$ band) with a concomitant decrease of other secondary structure contributions.

These data support the concept that in vivo the scissible bond in the Arg-Lys doublet is situated in the vicinity of a $\beta$-turn structure. However, the proportions of S-14 and S-28, recovered from cell extracts of $\left[\mathrm{G}^{-5}\right],\left[\mathrm{S}^{-5}-\mathrm{N}^{-3}\right]$ and $\left[\mathrm{Y}^{-5}-\mathrm{G}^{-3}\right]$ mutants, were not similar to that found in the case of the wild type (Table 3). These observations underline the importance of certain structural features other than the sole $\beta$-turn structure in specifying correct processing at both cleavage sites.

\subsection{Role of $P-(X)_{3}-P$ motif in the conformation of $S-28(1-12)$ domain}

The presence of proline residues, arranged as $\mathrm{P}-(\mathrm{X})_{3}-\mathrm{P}$ pattern in $\mathrm{S}-28(1-12)$ sequence, might be responsible for the differences observed precedently. In order to evaluate the potential role(s) of this motif in prosomatostatin processing, different mutants were constructed in which the $\mathrm{P}-(\mathrm{X})_{3}-\mathrm{P}$ motif was either deleted or mutated.

Results presented in Table 3 underline large differences in the processing of mutants in which the $\mathrm{P}^{-5}$ A-M-A-P ${ }^{-9}$ pattern was partially deleted. Indeed, the ratio of S-28 to S-14 produced, which was 1 in 

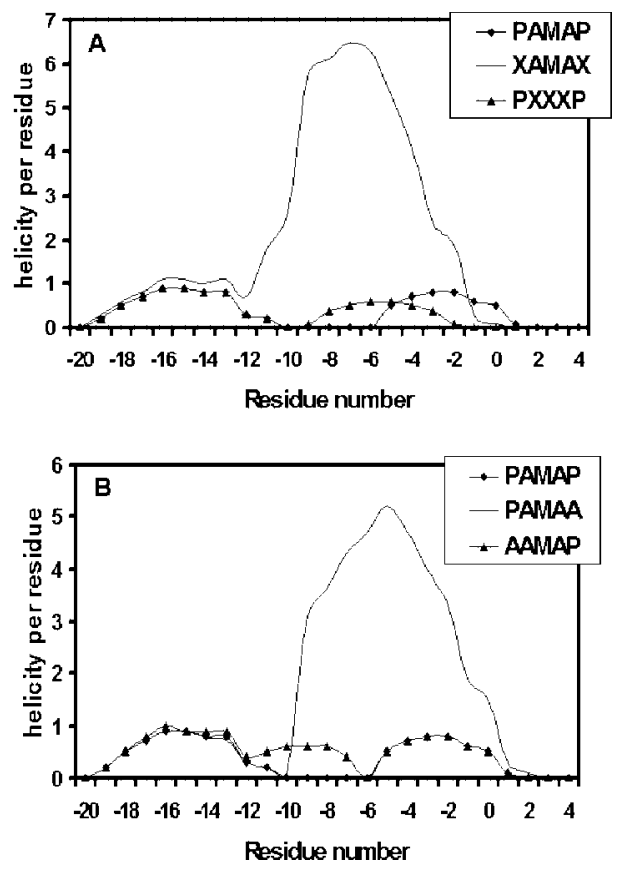

Fig. 9. Secondary structure prediction of the human prosomatostatin sequence Som-28(1-12). Helicity per residue calculated for peptides in which $(\mathrm{A})$ - the $\mathrm{P}^{-9}-(\mathrm{X})_{3}-\mathrm{P}^{-5}$ motif was partially deleted and $(\mathrm{B})-\mathrm{P}^{-5}$ or $\mathrm{P}^{-9}$ was mutated by Ala (from [36]).

cells expressing the non-mutated precursor [34], was reduced for the $\Delta[\mathrm{AMA}]$ mutant and raised for the $\Delta[\mathrm{PP}]$ mutant. Moreover, while increase in cleavage at either the monobasic $(\Delta[\mathrm{PP}]$ mutant) or the diba$\operatorname{sic}(\Delta[\mathrm{AMA}]$ mutant) sites resulted in a decrease in cleavage at the other site, deletion of proline residues induced additionally a decrease in the processing efficiency of the $\Delta[\mathrm{PP}]$ mutant. Data, obtained by the AGADIR method [35], reveal also large variations in helical propensity of the sequences corresponding to these mutants (Fig. 9A). Indeed, deletion of the A-M-A tripeptide (PXXXP motif) decreased exclusively the helicity values per residue of the dibasic site containing domain whereas deletion of proline residues (XAMAX motif) increased both the helicity values and the size of the helical sequence. Together, these results emphasize the functional role of the $\mathrm{P}^{-5}-\mathrm{A}-\mathrm{M}-\mathrm{A}-\mathrm{P}^{-9}$ motif in the generation of equal amounts of S-28 and S-14 from their common precursor. It is noteworthy that statistical studies have revealed that, amongst the $\mathrm{P}-(\mathrm{X}) n-\mathrm{P}$ patterns analyzed in proteins, the $\mathrm{P}-(\mathrm{X})_{3}-\mathrm{P}$ motif is the most frequent [30].

Final demonstration of the importance of the $\mathrm{P}-(\mathrm{X})_{3}-\mathrm{P}$ pattern was provided by examination of prosomatostatin mutants in which proline residues were mutated. As shown in Table 3, replacement of $\mathrm{P}^{-9}$ or $\mathrm{P}^{-5}$ by Ala ( $\alpha$-helix promoting residue) almost abolished selectively the cleavage of the precursor at the monobasic ([ $\left.\mathrm{A}^{-9}\right]$ mutant) and the dibasic ([ $\left.\mathrm{A}^{-5}\right]$ mutant) sites. Structural effects induced by these substitutions were firstly investigated by the AGADIR method. Analysis of helicity profiles, obtained for the S-28(1-12) sequences bearing these mutations (Fig. 9B), indicated that substitution of proline residues by Ala favored the extension of an $\alpha$-helix towards the dibasic site (from $\mathrm{N}^{-10}$ to $\mathrm{G}^{+2}$ for the $\mathrm{A}^{-5}$ mutation: PAMAA motif) and the monobasic one (from $\mathrm{N}^{-12}$ to $\mathrm{P}^{-5}$ for the $\mathrm{A}^{-9}$ mutation: AAMAP motif), respectively. Secondly, conformational analysis of synthetic peptides, corresponding to these mutations, was performed by CD and IR spectroscopies [36]. Table 4 summarizes the percentage of $\alpha$-helix 
Table 4

Helical content of Som $(-15-+2)$-derived peptides

\begin{tabular}{lcc}
\hline Peptides & \multicolumn{2}{c}{$\% \alpha$-helix } \\
\cline { 2 - 3 } $\mathrm{CD}^{\mathrm{a}}$ & $\mathrm{IR}^{\mathrm{b}}$ \\
\hline Som $(-15-+2)$ & $\mathbf{2 7}$ & $\mathbf{2 7}$ \\
{$\left[\mathrm{A}^{-5}\right]-\operatorname{Som}(-15-+2)$} & $\mathbf{4 4}$ & $\mathbf{3 7}$ \\
{$\left[\mathrm{A}^{-9}\right]-\operatorname{Som}(-15-+2)$} & $\mathbf{3 7}$ & $\mathbf{3 0}$ \\
\hline${ }^{\mathrm{a}}$ The percentage values of $\alpha$-helix were calculated from CD \\
spectra using the Fasman method $[22,23]$. \\
b The percentage values of $\alpha$-helix determined from FT-IR \\
spectra using curve-fitting procedures [37-41].
\end{tabular}

estimated from their CD and IR spectra [36]. Altogether, CD and FTIR results, in agreement with the predictions from the AGADIR method, underline the respective role of each proline residue in both the stability and the precise location of the helical structure adopted by the A-M-A tripeptide motif.

The major emerging concept from this study is that the $\mathrm{P}^{-5}-\mathrm{A}-\mathrm{M}-\mathrm{A}-\mathrm{P}^{-9}$ motif is an helicalpromoting seed whose integrity is essential for alternative prosomatostatin processing at both basic cleavage sites.

\section{Conclusion}

In this work was illustrated the usefulness of combined spectroscopical techniques and enzymatic studies in vitro, paralleled by in vivo/in vitro site-directed mutagenesis analysis of the selective effects of various mutations, in establishing the functional role of secondary structure in peptide hormone precursors. These observations provide a new example about the key participation of exposed structural motifs in protein recognition by converting endoproteolytic enzymes called also prohormones convertases $[4$, 6]. Similar conclusions were reached in studies of signal peptide excision [42], peptide hormone active forms [43], protein phosphorylation [44], glycosylation of precursors [45] and signal receptor-mediated internalization of lipoproteins [46].

Albeit no crystal structure of precursors so far has emerged, this type of approach should encourage future work on the 3D-structure of particular protein models in structure-function relationships investigations combining high performance spectroscopy and in vivo experiments. It can be envisioned that, in the near future, from stimulating research on pro-proteins and pro-peptides will emerge an heuristic and accurate view on processing mechanisms at the molecular level. This should provide a solid basis for the design of compounds capable to interfere selectively with these essential cellular processes. They might prove useful in the atriogenic control of certain dysregulations resulting from inappropriate protein post-translational modifications which play a central role in a wide range of cellular events.

\section{Acknowledgements}

This work was supported in part by funds from Université Pierre et Marie Curie and the CNRS to UMR7631 and by a France-Alzheimer doctoral fellowship to M.P. 


\section{References}

[1] P. Andrews, K. Brayton and J. Dixon, Precursors to regulatory peptides: their proteolytic processing, Experientia 43 (1987), 784-790.

[2] N. Darby and D. Smyth, Endopeptidases and prohormone processing, Biosci. Rep. 10 (1990), 1-13.

[3] J. Bourdais and P. Cohen, Post-translational proteolytic maturation of prosomatostatin, Cellular and molecular approach, Ann. Endocrinol. 52 (1991), 339-347.

[4] N. Seidah, R. Day, M. Marcinkiewicz and M. Chrétien, Precursor convertases: an evolutionary ancient, cell-specific, combinatorial mechanism yielding diverse bioactive peptides and proteins, Ann. N. Y. Acad. Sci. 839 (1998), 9-24.

[5] J. Creemers, R. Jackson and J. Hutton, Molecular and cellular regulation of prohormone processing, Semin. Cell Dev. Biol. 9 (1998), 3-10.

[6] A. Zhou, G. Webb, X. Zhu and D. Steiner, Proteolytic processing in the secretory pathway, J. Biol. Chem. 274 (1999), $20745-20748$.

[7] M. Rholam, P. Nicolas and P. Cohen, Precursors for peptide hormones share common secondary structures forming features at the proteolytic processing sites, FEBS Lett. 207 (1986), 1-6.

[8] L. Devi, Consensus sequence for processing of peptide precursors at monobasic sites, FEBS Lett. 280 (1991), 189-194.

[9] J. Veenstra, Mono- and dibasic proteolytic cleavage sites in insect neuroendocrine peptide precursors, Arch. Insect. Biochem. Physiol. 43 (2000), 49-63.

[10] E. Bek and R. Berry, Prohormonal cleavage sites are associated with omega loops, Biochemistry 29 (1990), 178-183.

[11] G. Rose, L. Gierash and J. Smith, Turns in peptides and proteins, Adv. Protein Chem. 34 (1985), 1-109.

[12] C. Ring, D. Kneller, R. Langridge and F. Cohen, Taxonomy and conformational analysis of loops in proteins, J. Mol. Biol. 224 (1992), 685-699.

[13] M. Rholam and P. Cohen, Stategies of processing enzyme characterization: Techniques for the determination of prohormone conformation and its role in processing, in: Neuroprotocols: A Companion to Methods in Neuroscience, M. Beinfeld, ed., Acad. Press Publishers, 1994, pp. 130-143.

[14] M. Rholam and P. Cohen, Peptides as tools for studying propeptide and proprotein processing, Anal. Chim. Acta 352 (1997), 155-178.

[15] C. Creminon, M. Rholam, H. Boussetta, N. Marrakchi and P. Cohen, Synthetic peptide substrates as models to study a pro-ocytocin/neurophysin converting enzyme, J. Chromatogr. 440 (988), 439-448.

[16] I. Plevrakis, C. Clamagirand, C. Creminon, N. Brakch, M. Rholam and P. Cohen, Proocytocin/neurophysin convertase from bovine neurohypophysis and corpus luteum secretory granules: complete purification, structure-function relationships, and competitive inhibitor, Biochemistry 28 (1989), 2705-2710.

[17] N. Brakch, H. Boussetta, M. Rholam and P. Cohen, Processing endoprotease recognizes a structural feature at the cleavage site of peptide prohormones. The pro-ocytocin/neurophysin model, J. Biol. Chem. 264 (1989), 15912-15916.

[18] M. Rholam, P. Cohen, N. Brakch, L. Paolillo, A. Scatturin and C. Di Bello, Evidence for beta-turn structure in model peptides reproducing pro-ocytocin/neurophysin proteolytic processing site, Biochem. Biophys. Res. Commun. 168 (1990), 1066-1073.

[19] L. Paolillo, M. Simonetti, N. Brakch, G. D'Auria, M. Saviano, M. Dettin, M. Rholam, A. Scatturin, C. Di Bello and P. Cohen, Evidence for the presence of a secondary structure at the dibasic processing site of prohormone: the pro-ocytocin model, EMBO J. 11 (1992), 2399-2405.

[20] L. Falcigno, L. Paolillo, G. D’Auria, M. Saviano, M. Simonetti and C. Di Bello, NMR conformational studies on a synthetic peptide reproducing the [1-20] processing domain of the pro-ocytocin-neurophysin precursor, Biopolymers 39 (1996), 837-848.

[21] N. Brakch, M. Rholam, H. Boussetta and P. Cohen, Role of beta-turn in proteolytic processing of peptide hormone precursors at dibasic sites, Biochemistry 32 (1993), 4925-4930.

[22] S. Venyaminov and J. Yang, in: Circular Dichroism and the Conformational Analysis of Biomolecules, Fasman, ed., Plenum Press, New York, 1996, pp. 69-107.

[23] R. Woody and A. Dunker, in: Circular Dichroism and the Conformational Analysis of Biomolecules, Fasman, ed., Plenum Press, New York, 1996, pp. 109-157.

[24] J. Jurka and T. Smith, Beta-turn-driven early evolution: the genetic code and biosynthetic pathways, J. Mol. Evol. 25 (1987), 15-19.

[25] J. Spouge, H. Guy, J. Cornette, H. Margalit, K. Cease, J. Berzofsky and C. DeLisi, Strong conformational propensities enhance T cell antigenicity, J. Immunol. 38 (1987), 204-212.

[26] T. Hynes, R. Kautz, M. Goodman, J. Gill and R. Fox, Transfer of a beta-turn structure to a new protein context, Nature 339 (1989), 73-76.

[27] R. Monsalve, L. Menendez-Arias, C. Lopez-Otin and R. Rodriguez, Beta-turns as structural motifs for the proteolytic processing of seed proteins, FEBS Lett. 263 (1990), 209-212. 
[28] J. Richardson and D. Richardson, Amino acid preferences for specific locations at the end of $\alpha$ helices, Science 240 (1988), 1648-1652.

[29] G. Von Heijne, Proline kinks in transmembrane alpha-helices, J. Mol. Biol. 18 (1991), 499-503.

[30] M. MacArthur and J. Thornton, Influence of proline residues on protein conformation, J. Mol. Biol. 218 (1991), $397-412$.

[31] G. Vanhoof, F. Goossens, I. De Meester, D. Hendriks and S. Scharpe, Proline motifs in peptides and their biological processing, FASEB J. 8 (1995), 736-744.

[32] S. Gomez, G. Boileau, L. Zollinger, C. Nault, M. Rholam and P. Cohen, Site-specific mutagenesis identifies amino acid residues critical in prohormone processing, EMBO J. 8 (1989), 2911-2916.

[33] N. Brakch, G. Boileau, M. Simonetti, C. Nault, P. Joseph-Bravo, M. Rholam and P. Cohen, Prosomatostatin processing in Neuro2A cells. Role of beta-turn structure in the vicinity of the Arg-Lys cleavage site, Eur. J. Biochem. 16 (1993), 39-47.

[34] N. Brakch, M. Rholam, C. Nault, G. Boileau and P. Cohen, Differential processing of hormone precursor. Independent production of somatostatins 14 and 28 in transfected neuroblastoma 2A cells, FEBS Lett. 282 (1991), 363-367.

[35] V. Munoz and L. Serrano, Elucidating the folding problem of helical peptides using empirical parameters, Nat. Struct. Biol. J. 1 (1994), 399-409.

[36] N. Brakch, N. Lazar, M. Panchal, F. Allemandou, G. Boileau, P. Cohen and M. Rholam, The somatostatin-28(1-12)NPAMAP sequence: an essential helical-promoting motif governing prosomatostatin processing at mono- and di-basic sites, Biochemistry 41 (2002), 1630-1639.

[37] D. Byler and H. Susi, Examination of the secondary structure of proteins by deconvolved FTIR spectra, Biopolymers 25 (1986), 469-487.

[38] D. Lee, P. Haris, D. Chapman and R. Mitchell, Determination of protein secondary structure using factor analysis of infrared spectra, Biochemistry 29 (1990), 9185-9193.

[39] D. Kennedy, M. Crisma, C. Toniolo and D. Chapman, Studies of peptides forming 3(10)- and alpha-helices and beta-bend ribbon structures in organic solution and in model biomembranes by Fourier transform infrared spectroscopy, Biochemistry 30 (1991), 6541-6548.

[40] W. Surewicz, H. Mantsch and D. Chapman, Determination of protein secondary structure by Fourier transform infrared spectroscopy: a critical assessment, Biochemistry 32 (1993), 389-394.

[41] R. Pribic, I. van Stokkum, D. Chapman, P. Haris and M. Bloemendal, Protein secondary structure from Fourier transform infrared and/or circular dichroism, Anal. Biochem. 214 (1993), 366-378.

[42] G. Duffaud and R. Hider, Signal peptidases recognize a structural feature at the cleavage site of secretory proteins, J. Biol. Chem. 263 (1988), 10224-10 228.

[43] J. Ball and P. Alewood, Conformational constraints: nonpeptide beta-turn mimics, J. Mol. Recognit. 3 (1990), 55-64.

[44] D. Tinker, E. Krebs, I. Feltham, S. Attah-Poku and V. Ananthanarayanan, Synthetic beta-turn peptides as substrates for a tyrosine protein kinase, J. Biol. Chem. 263 (1988), 5024-5026.

[45] I. Laczko, M. Hollosi, L. Urge, K. Ugen, D. Weiner, H. Mantsch, J. Thurin and L. Otvos, Synthesis and conformational studies of N-glycosylated analogues of the HIV-1 principal neutralizing determinant, Biochemistry 31 (1992), 4282-4288.

[46] J. Collawn, M. Stangel, L. Kuhn, V. Esekogwu, S. Jing, I. Trowbridge and J. Tainer, Transferrin receptor internalization sequence YXRF implicates a tight turn as the structural recognition motif for endocytosis, Cell 63 (1990), 1061-1072. 


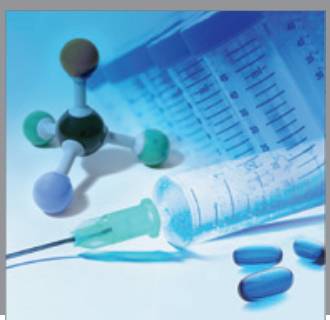

International Journal of

Medicinal Chemistry

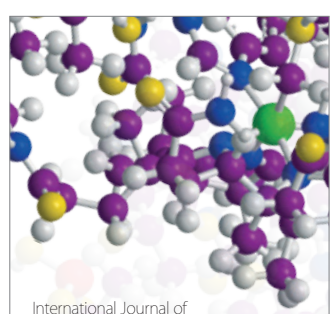

Carbohydrate Chemistry

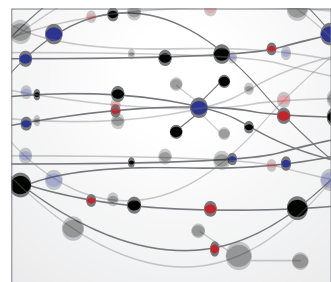

The Scientific World Journal
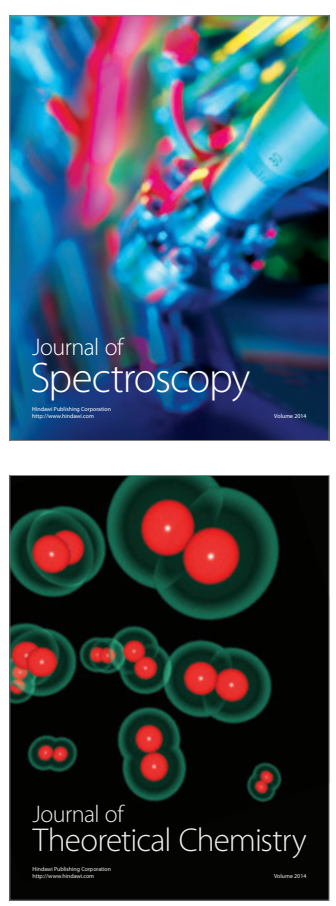
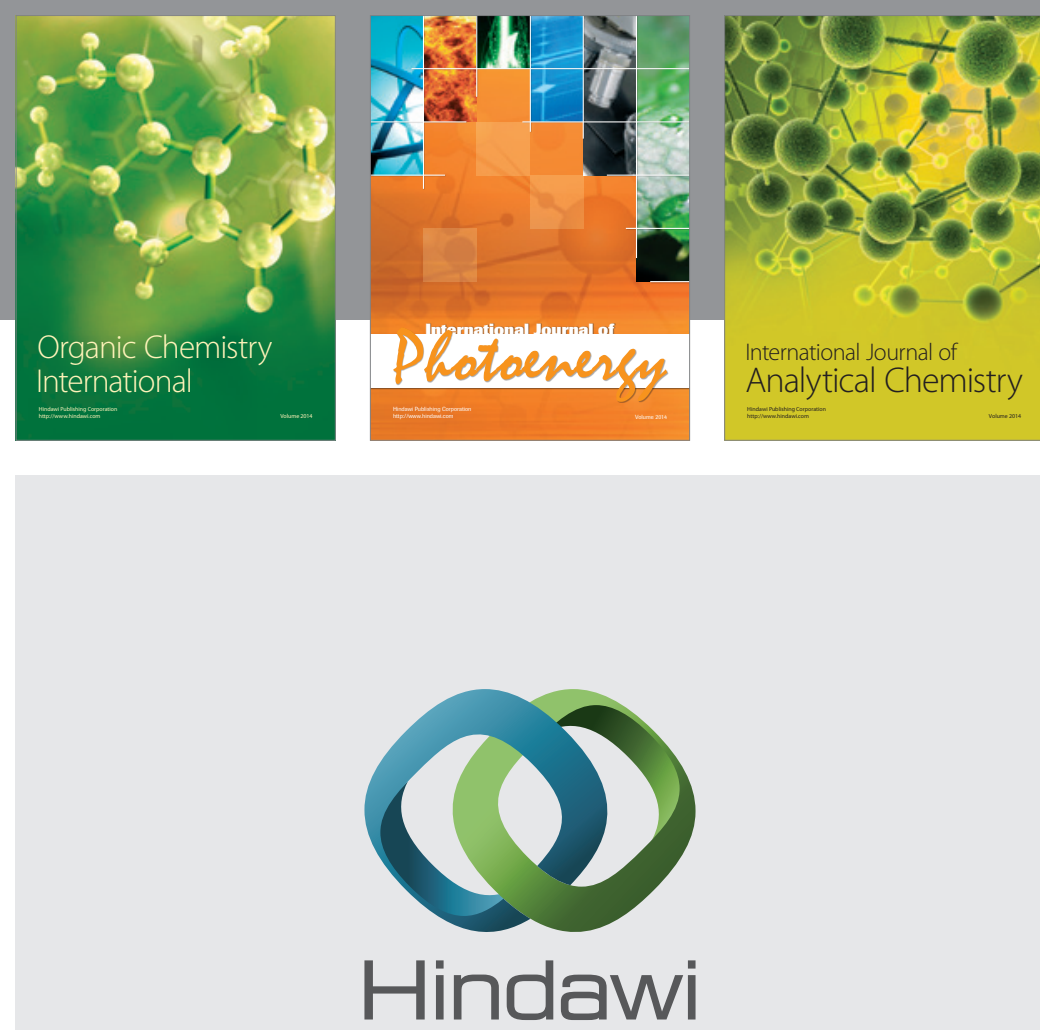

Submit your manuscripts at

http://www.hindawi.com
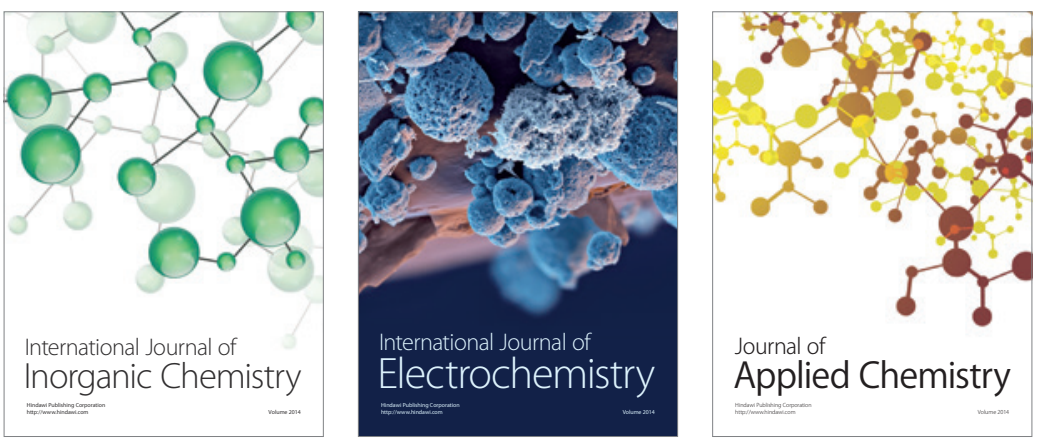

Journal of

Applied Chemistry
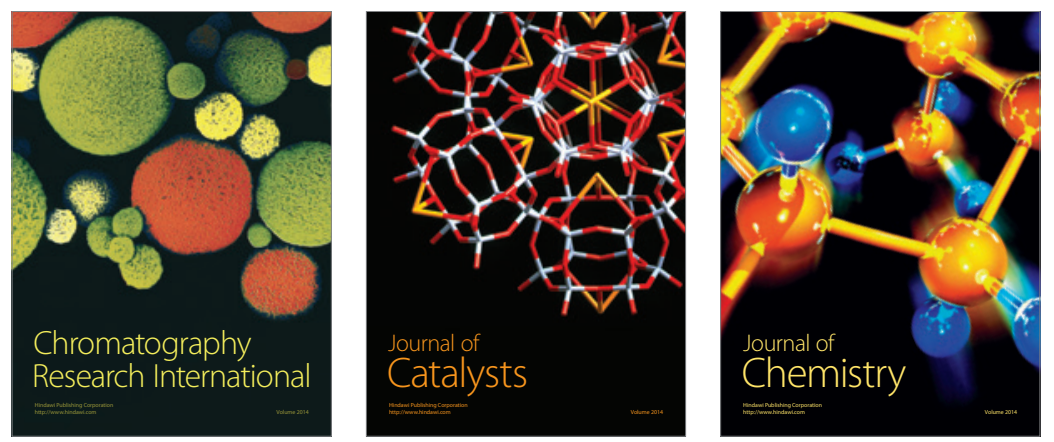
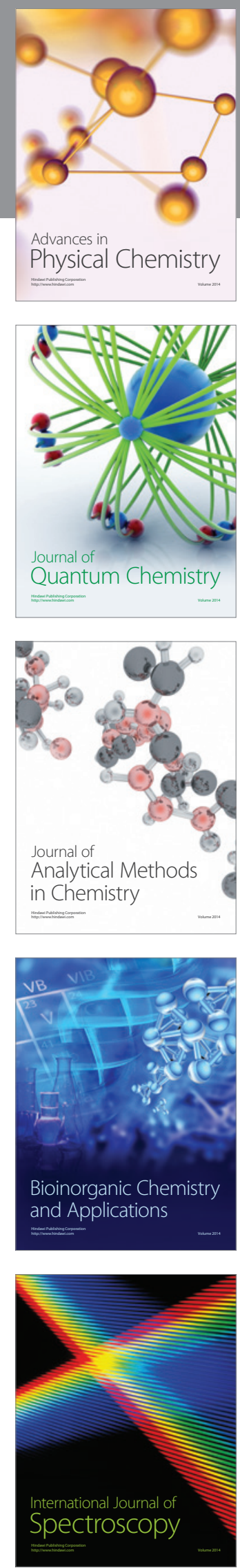